\title{
A fatigue life calculation method for structural elements made of D16CzATW aluminium alloy
}

\author{
Józef Szala, Prof. \\ Grzegorz Szala, Ph. D. \\ University of Technology and Life Science, Bydgoszcz
}

\begin{abstract}
In the calculating of fatigue life of structural elements the methods based on hypotheses of fatigue damage summation are commonly applied. In using the methods, apart from choice of an appropriate hypothesis, it is necessary to know a loading spectrum which usually constitutes a set of sinusoidal cycles of variable parameters $\left(S_{,}, S_{m}\right)$, as well as fatigue characteristics in the form of Wöhler fatigue diagram, as a rule. Knowledge of the above mentioned data is low during structural design process as designed material objects and possibility of performing measurements are lacking.

Hence in this work a calculation method of fatigue life of structural elements, based on the relations between fatigue life diagrams determined in constant-amplitude conditions (Wöhler diagrams) and those obtained under programmed or random loads, is described. The proposed method was experimentally verified by using results of fatigue tests on structural elements made of D16CzATW aluminium alloy.
\end{abstract}

Keywords: fatigue life, structutral elements, D16CzATW aluminium alloy

\section{INTRODUCTION}

Lack of a coherent theory of fatigue process of materials including metals and their alloys makes that for engineering applications are used phenomenological hypotheses on summation of damages, whose description can be found a.o. in the monographs [1] and [2]. Out of many hypotheses, the oldest hypothesis, most comprehensively verified and commonly used is that based on linear summation of fatigue damages, given by Palmgren and Miner (P-M). In many cases its experimental verification showed a low conformity between results of fatigue life calculations and experimental tests, that has resulted in undertaking further efforts to elaborate new calcultation methods $[3,4,5,6]$. For the calculations with the use of the damage summation hypotheses it is necessary to know additionally operational loads (stresses or strains) given in the form of loading spectra, as well as an appropriate fatigue diagram. Such loading spectra are elaborated by applying the cycle - counting methods described in [7], in order to obtain a set of sinusoidal cycles equivalent, as regards fatigue life, to random loading. The third item necessary for the calculations is a Wöhler fatigue diagram of parameters appropriate to a type of loading spectrum. The diagram can be determined experimentally or, if not possible, selected from catalogues or literature sources $[8,9]$. Out of the above mentioned main elements of the calculating algorithm, the largest uncertainty is associated with the fatigue damage summation hypothesis. Experimental verification of P-M hypothesis, performed by means of a few hundred tests revealed the difference between results of the experiments and calculations ranging from 0,3 to 30 -fold $[10,11]$. The drawbacks of the method have been very clearly felt in structural design process where accurate data on operational loads, material cyclic properties and damage summation hypothesis, are lacking.

It is then necessary to elaborate, excepting damage summation hypothesis, a simple calculation method based on assessment of main loading spectrum parameters and basic cyclic properties of material. To the above mentioned conditions corresponds the method based on statistical relations between fatigue life determined under sinusoidal load conditions (described by Wöhler diagram) and that determined under random load conditions or programmed ones (described by Gassner diagram).

As observed in the fatigue life tests of structural elements under programmed load conditions (block spectra, usually) corresponding to operational loading, their test results depended on a level of variable loads and shape of loading spectra. Such relationship for steel elements was demonstrated in [10] and [12], and for aluminium elements - in [13]. The problem was also described in the monograph of Haibach [14] and the information bulletins of Germanischer Lloyd Group, a ship classification society, [15] and [16].

As proved in the experimental verification of the calculation method based on statistical relations between Wöhler and Gassner diagrams, performed on steel specimens and structural elements, the calculation results obtained with its use, have been 
closer to results from experimental tests than those achieved from the calculations to which Palmgren-Miner hypothesis on damage summation was applied, [17].

In the work [17] was analyzed an influence of a shape of loading spectrum on results of experimental verification of calculation method of fatigue life of steel specimens and elements.

This work is aimed at extending the method onto aluminiumalloy elements, in which data determined from plain specimens are applied to calculation of geometrically notched elements and structural elements.

\section{FORMULATION OF THE PROBLEM}

The method proposed in this paper is based on the following assumptions:

a) damage cumulation process is qualitatively independent on loading spectrum,

b) fatigue damage cumulation depends quantitatively on parameters of loading spectrum (its shape and maximum load),

c) constant-amplitude loading is a special case of loading spectrum elaborated on the basis of random loads, e.g. block spectrum,

d) if number of cycles in a loading spectrum (for a specimen or structural element) is reduced to one, then fatigue life diagrams intersect each other in the same point; it means that the spectral form loses its sense,

e) for different loading spectra of the same maximum load value, fatigue life of a specimen or structural element depends mainly on a form of a spectrum.

a)

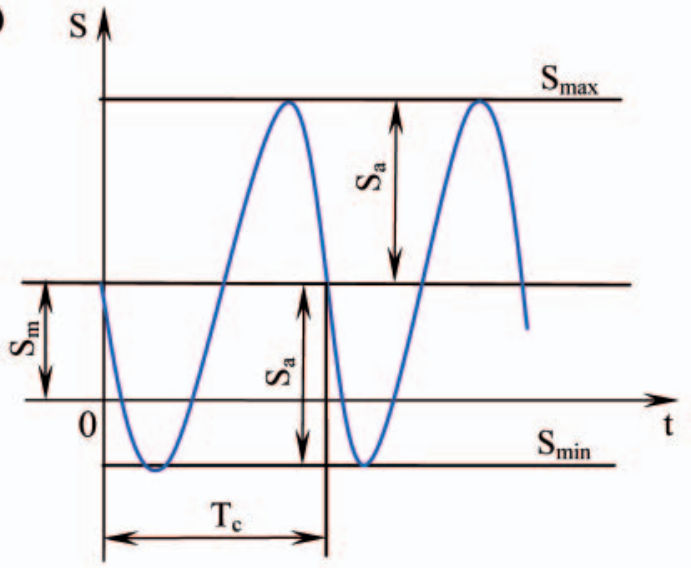

c)

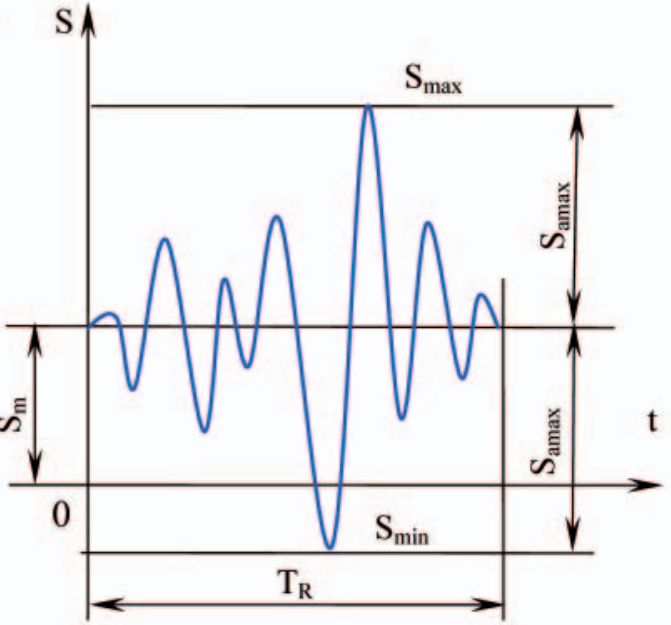

In Fig. 1 the sinusoidal loading, random loading and loading spectra corresponding to them are schematically presented.

Loading spectrum form is characterized by the diagram filling factor calculated from the formula as follows [7]:

$$
\zeta=\frac{1}{\mathrm{~S}_{\mathrm{a} \max }} \sum_{\mathrm{i}=1}^{\mathrm{k}} \mathrm{S}_{\mathrm{ai}} \mathrm{t}_{\mathrm{i}}
$$

which, in relation to the schematic spectrum diagram, is equivalent to the ratio of the areas $F_{1}$ (under the block spectrum envelope) to the area of the rectangle having the sides: $\mathrm{S}_{\text {amax }}$ and $n_{c}$. As results from the scheme (b) in Fig. 1 and the formula (1), the spectrum filling factor $\zeta$ is equal to 1.0 for sinusoidal loading, and for random loading amounts to $\zeta<1.0$. The smaller value of the diagram filling factor the slighter loading conditions for structural element; an example of mutual location of the fatigue-life diagrams for various values of the diagram filling factor is presented in Fig. 2.

The schematic procedure of the calculation complying with the above specified assumptions is presented in Fig. 3. The Wöhler diagram (W) and Gassner diagram (G) which intersect each other in the point $\mathrm{c}=\mathrm{c}_{0}$, are described by the expressions:

- for the Wöhler diagram:

$$
\log \mathrm{S}_{\mathrm{a}}=-\frac{1}{\mathrm{~m}_{0}} \log \mathrm{N}+\mathrm{c}_{0}
$$

- for the Gassner diagram:

$$
\log \mathrm{S}_{\mathrm{a} \max }=-\frac{1}{\mathrm{~m}} \log \mathrm{N}_{\mathrm{C}}+\mathrm{c}
$$
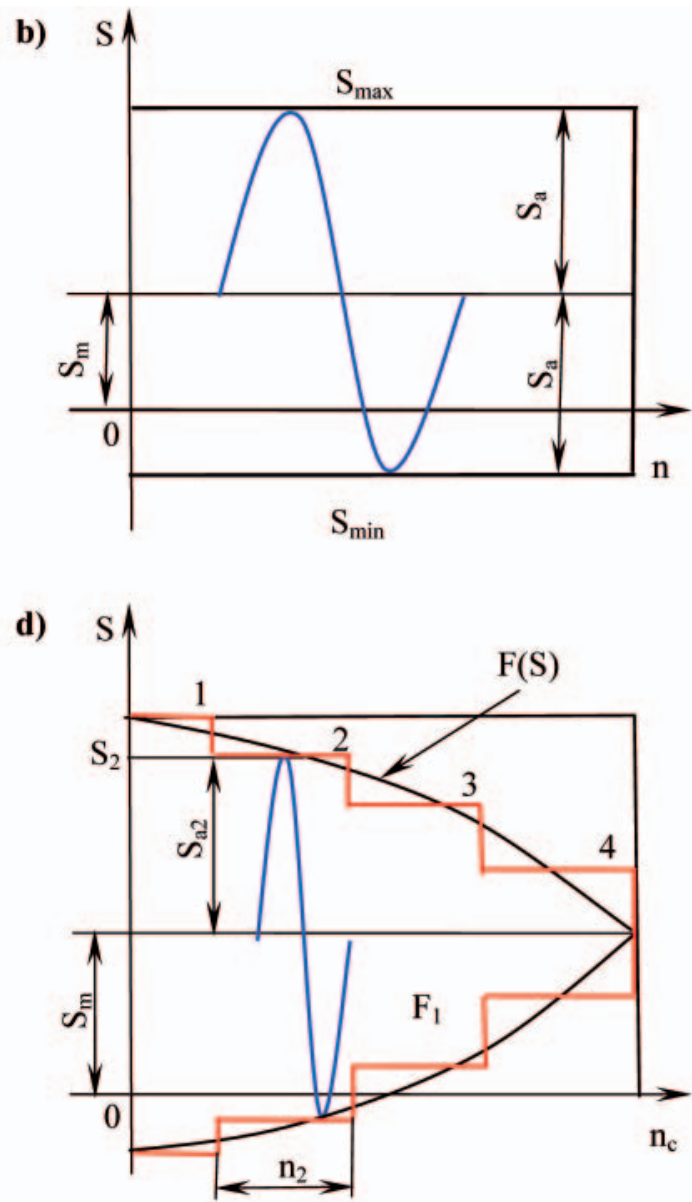

Fig. 1. Schematic loading diagrams and relevant loading spectra: a) sinusoidal loading, b) sinusoidal loading spectrum, c) random loading, d) random loading spectrum 
a)

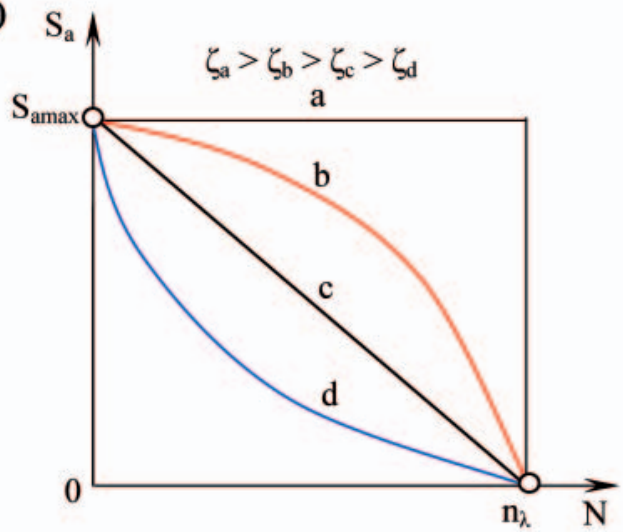

b)

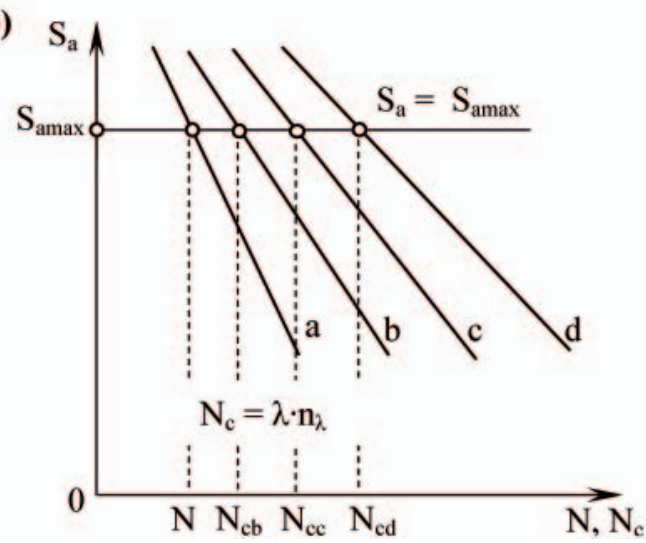

Fig. 2. Schematic diagram of fatigue life dependence on loading spectrum form

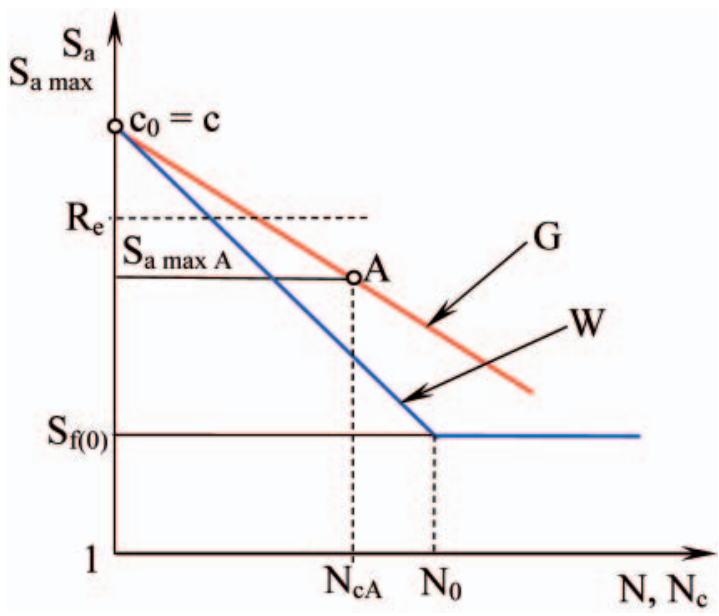

Fig. 3. Schematic diagram for fatigue life calculation

From the scheme of Fig. 3 results the possibility of determining Gassner diagram on the basis of knownledge of Wöhler fatigue diagram and an arbitrary point of the Gassner diagram under determination. The fact is of a great importance for shortening time of tests because it requires to perform programmed fatigue tests (which are time-consuming) for only one point of Gassner diagram (a few fatigue tests at only one, of maximum load, level of the spectrum).

For $\mathrm{S}_{\text {amax }}=\mathrm{S}_{\mathrm{a}}$ and $\mathrm{c}_{0}=\mathrm{c}$ l, by comparing the formulae (2) and (3) to each other the following is achieved:

$$
\log \mathrm{N}_{\mathrm{C}}=\frac{\mathrm{m}}{\mathrm{m}_{0}} \log \mathrm{N}
$$

The relation $\mathrm{m} / \mathrm{m}_{0}$ in function of the diagram filling factor $\zeta$, for different kinds of steel specimens and elements, was experimentally determined in the following form, $[10,17]$ :

$$
\frac{\mathrm{m}}{\mathrm{m}_{0}}=\varsigma^{-\mathrm{r}}
$$

The power exponent $r$ is contained within the range of 0.2 $\div 0.4$. It should be stressed that if one of the lower values of the range is assumed then conservative results (i.e. lower fatigue life values) are obtained.

On determination of $\mathrm{N}$ from the formula describing Wöhler diagram is obtained:

$$
\mathrm{N}=\left(\frac{\mathrm{C}_{0}}{\mathrm{~S}_{\mathrm{a}}}\right)^{\mathrm{m}_{0}}
$$

and on substitution of the formula (5) to the formula (4) the following is obtained, after transformations:

$$
\log \mathrm{N}_{\mathrm{C}}=\varsigma^{-\mathrm{r}} \mathrm{m}_{0} \log \frac{\mathrm{C}_{0}}{\mathrm{~S}_{\mathrm{amax}}}
$$

It should be explained that $\mathrm{c}_{0}$ which appears in the formula (2), is equal to $\log \mathrm{C}_{0}$ which appears in the formulae (6) and (7).

The experimental verification of the desribed calculation method, performed for specimens and bonded structural joints for three values of the diagram filling factor $\zeta(0.34 ; 0.56$ and 0.77 ), showed a conformity of the results obtained from the calculation in question with those from the tests higher than in the case of the results from the calculation where selected fatigue damage summation hypotheses were applied.

\section{TESTS AND CALCULATION RESULTS FOR SPECIMENS AND STRUCTURAL ELEMENTS MADE OF D16CZATW ALUMINIUM ALLOY}

\section{Method and program of the tests}

From the target of this work the necessity results to perform basic tests aimed at determination of static and cyclic properties of material used for objects to be tested, as well as verification tests of the calculation method of fatigue life of elements under variable random loads.

In the first group of the tests, apart from the monotonic tension test, Wöhler fatigue diagrams have to be determined, as well as the test aimed at determination of value of the power exponent $r$ appearing in the formula (5), has to be performed with the use of plain specimens under random loading conditions.

The determination method of value of the power exponent $r$ results from Fig. 3. For tests under random or programmed loading it is enough to have aWöhler diagram, to determine a point on Gassner fatigue-life diagram, the point A in Fig. 3, and, to form a complete Gassner's diagram of fatigue life by drawing the straight line containing the points A and c.

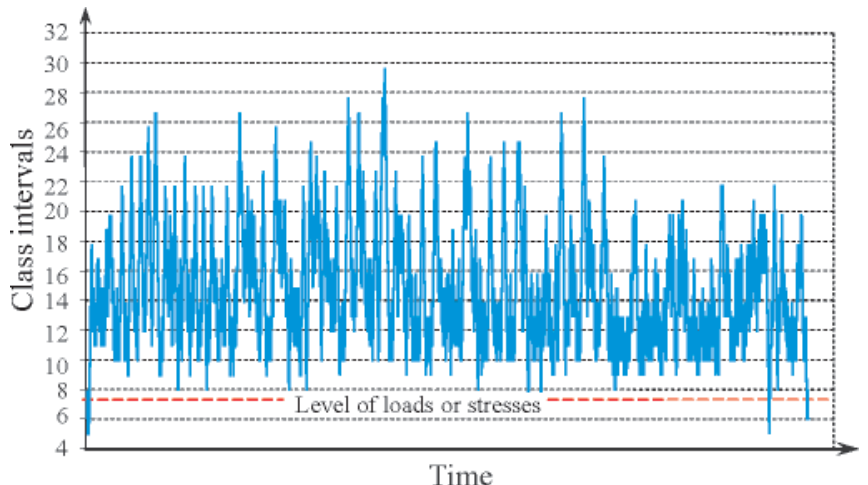

Fig. 4. Random loading assumed for the tests, according to the publication [18] 


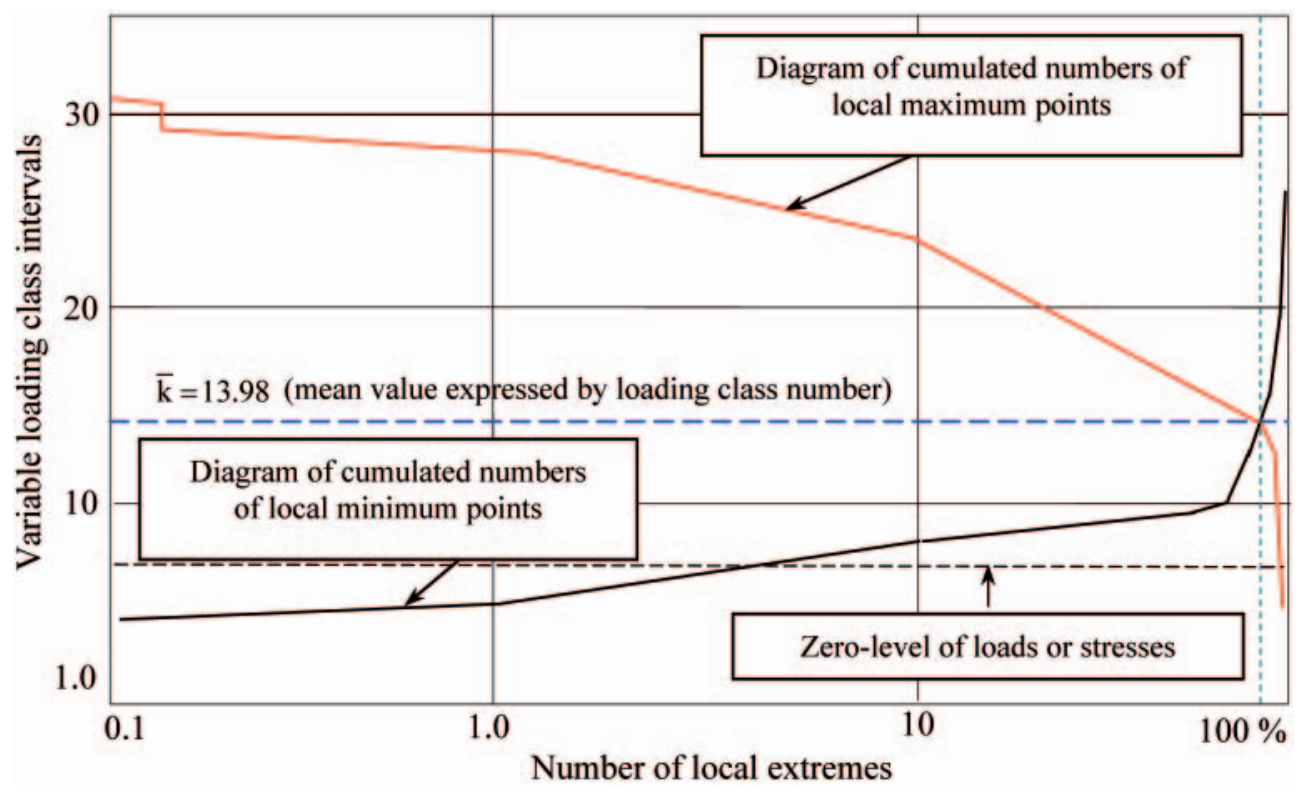

Fig. 5. Loading spectrum for the random loading of Fig. 4, obtained by using the method of counting local extremes

\section{Variable loading and its spectrum}

As an example operational loading the data contained in the publication FALSTAFF-130 [18] were taken. Its graphical form is shown in Fig. 4, and Fig. 5 contains its spectrum achieved by applying the local extremes counting method [7]. On the ordinate axis of the loading diagram, in compliance with the assumption of the FALSTAFF project, are given class intervals within which local extremes have been counted. Such approach to loading spectrum makes performing the tests on various levels of the maximum stress $\mathrm{S}_{\max }$, easier, necessary to determine fatigue life diagram for a tested object. The tests were conducted on a few levels of the maximum stress $\mathrm{S}_{\max }$ of the spectrum. The spectrum filling factor calculated from the formula (1) was equal to $\zeta=0.375$.

\section{The testing objects}

The testing objects made of D16CzATW aluminium alloy are shown in Fig. 6. Their basic mechanical properties including cyclic ones were determined with the use of the flat unnotched (plain) specimens whose shape and dimensions are given in Fig. 6a. The tests for verification of the calculation method in question were conducted on the plate specimens with rivet holes, Fig. 6b, as well as on the riveted structural element, Fig. 6c. The chemical composition of D16CzATW alloy of which the tested objects were manufactured, is given in Tab. 1.

\section{Results of the tests}

The monotonic tension test was conducted on the standard specimens acc. PN-EN 10002-1+AC1 standard (Fig. 6a) with the use of Instron 8502 test machine equipped with suitable instruments and programs. The test results are presented in Tab. 2.

In Tab. 3 are given the data concerning fatigue properties of D16CzATW aluminium alloy in the range of high-cyclic fatigue (HCF) under sinusoidal pulsating load conditions.

The complete Wöhler's diagram for the plain specimens, together with the depicted points of experimental results, is presented in Fig. 7.

The pulsating load conforms the best to the operational load assumed for the tests in question (Fig. 4).

\section{Experimental determination of value of the power exponent $r$}

In order to obtain a value of the power exponent $r$ the experiment was performed in compliance with the method above described in p. 3.1. To this end, the tests were conducted

Tab. 1. Chemical composition of D16CzATW aluminium alloy

\begin{tabular}{|c|c|c|c|c|c|c|c|}
\hline Alloy & $\mathbf{C u}$ & $\mathbf{M g}$ & $\mathbf{M n}$ & $\mathbf{Z n}^{(*)}$ & $\mathbf{F e}^{(*)}$ & $\mathbf{S i} \mathbf{i}^{(*)}$ & Other $^{(*)}$ \\
\hline D16Cz & $3.8 \div 4.9$ & $1.2 \div 1.8$ & $0.3 \div 0.9$ & 0.1 & 0.3 & 0.2 & 0.05 \\
\hline \multicolumn{8}{|c|}{ Pure alloy (Cz). cladded with AD1plating of normal thickness (A). in supersaturated and natural ageing state } \\
(T). intended for covering (W)
\end{tabular}

Tab. 2. Static properties of plates made of D16CZATW aluminium alloy

\begin{tabular}{|c|c|c|c|c|c|}
\hline $\begin{array}{c}\mathbf{R m} \\
{[\mathbf{M P a}]}\end{array}$ & $\begin{array}{c}\mathbf{R e} \\
{[\mathbf{M P a}]}\end{array}$ & $\begin{array}{c}\mathbf{R m} \\
{[\mathbf{M P a}]}\end{array}$ & $\begin{array}{c}\mathbf{E} \\
{[\mathbf{M P a}]}\end{array}$ & $\begin{array}{c}\mathbf{A} \\
{[\mathbf{\%}]}\end{array}$ & $\begin{array}{c}\mathbf{Z} \\
{[\mathbf{\%}]}\end{array}$ \\
\hline 460 & 336 & 613 & 68402 & 25.2 & 28.1 \\
\hline
\end{tabular}

Tab. 3. Cyclic properties of plates made of D16CzATW aluminium alloy

\begin{tabular}{|c|c|c|c|c|}
\hline Load & \multicolumn{2}{|c|}{ Wöhler equation } & Fatigue limit [MPa] & Limit number of cycles \\
\hline $\begin{array}{c}\text { Pulsating } \\
\mathrm{R}=0\end{array}$ & $\mathrm{~S}^{\mathrm{m}} \mathrm{N}=\mathrm{C}$ & $\begin{array}{r}\mathrm{m}=5.3107 \\
\mathrm{C}=2164.7\end{array}$ & $\mathrm{~S}_{\mathrm{f}(0)}=113.2$ & $\mathrm{~N}=6.4 \cdot 10^{6}$ \\
\hline
\end{tabular}


a)

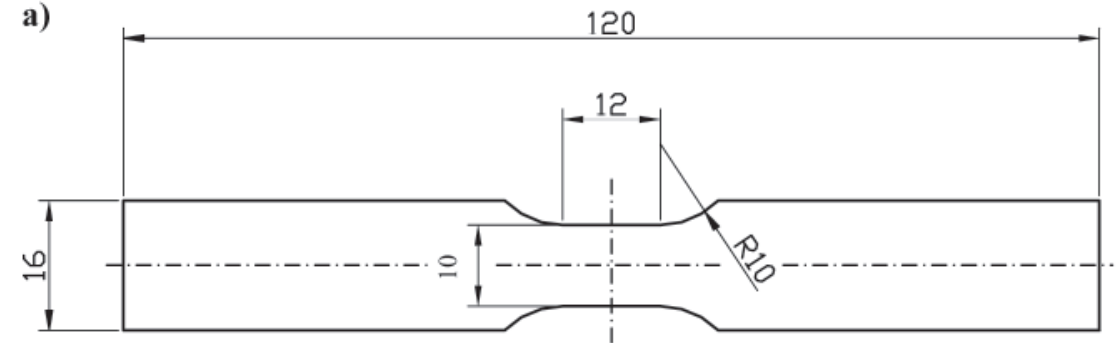

b)

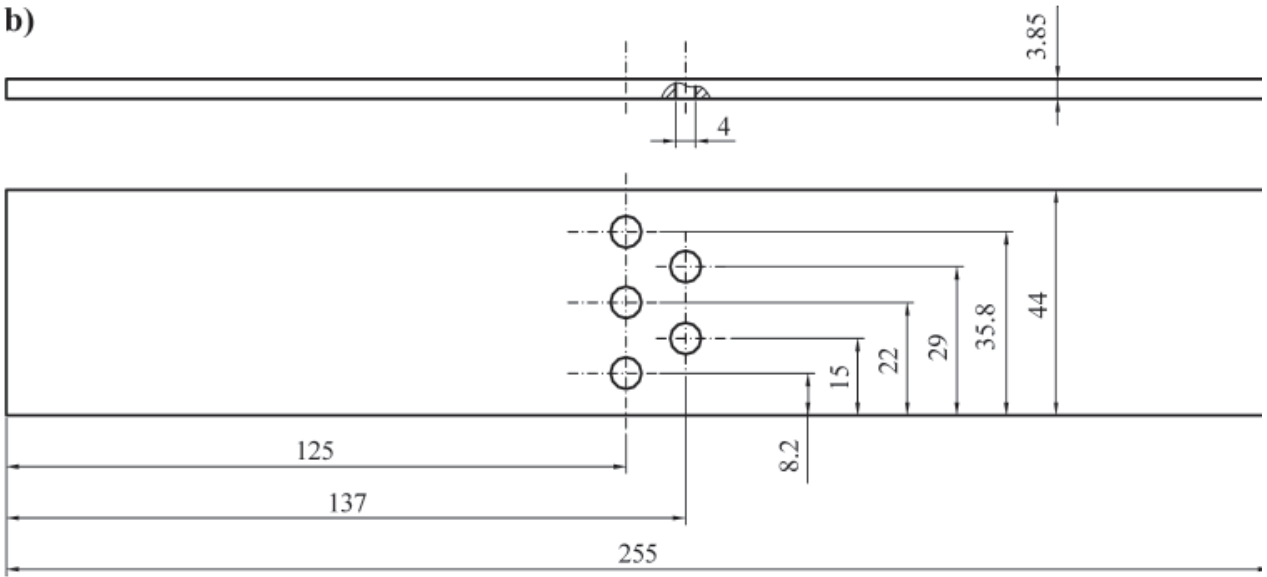

c)
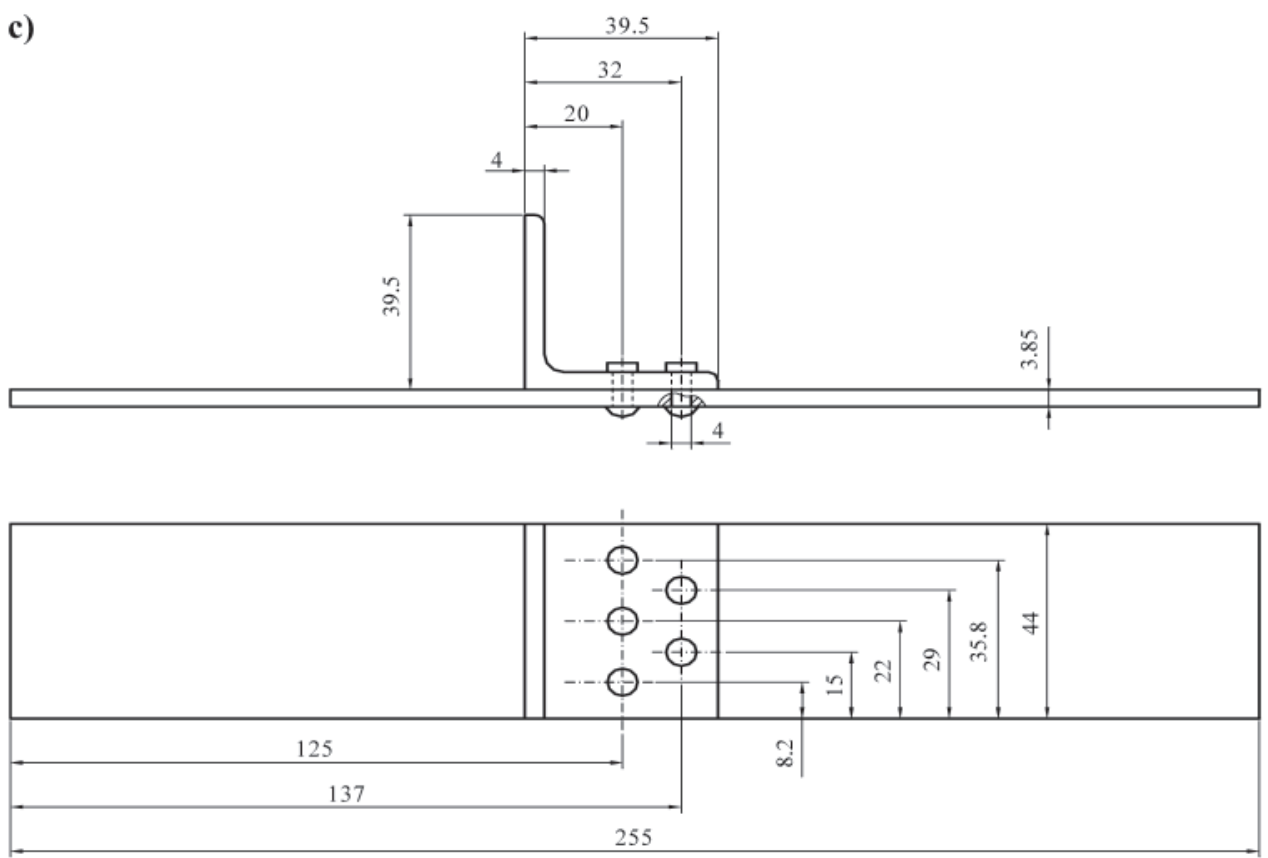

Fig. 6. The tested objects: a) the plain specimen prepared acc. PN-74/H-(04327 standard, b) the specimen with rivet holes, c) the riveted structural element

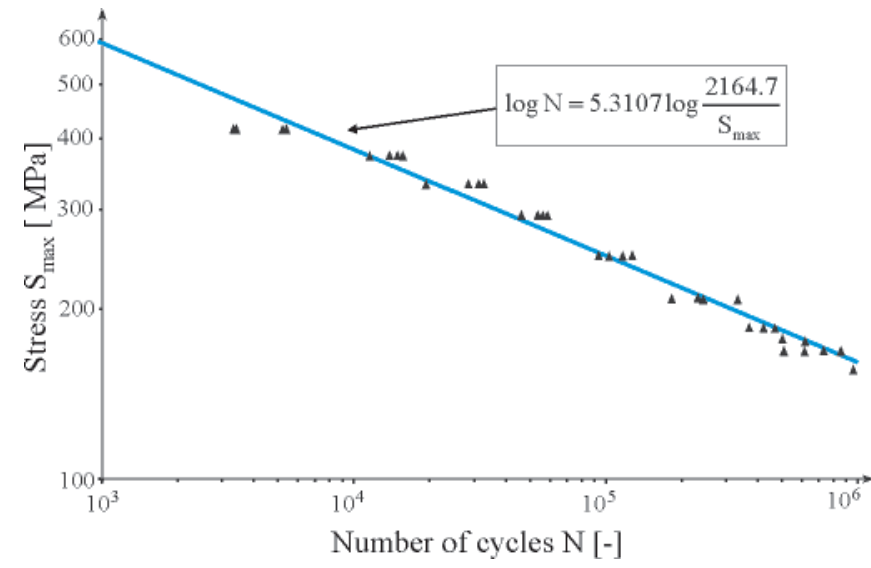

Fig. 7. Wöhler diagram for D16CzATW aluminium alloy, determined under pulsating stress conditions $(R=0)$ on six specimens under random loading conditions (Fig. 4) on the mean level of the maximum stress $\mathrm{S}_{\operatorname{maxA}}=350[\mathrm{MPa}]$. The fatigue-life test results are presented in Tab. 4. The mean fatigue life value amounts to $\mathrm{N}_{\mathrm{c}}=0,953$.

By transforming the formulae (4) and (5) the following is obtained:

hence:

$$
\zeta^{r}=\frac{\log N}{\log N_{C}}
$$

$$
r=\log \left(\frac{\log N}{\log N_{C}}\right) \cdot \frac{1}{\log S}
$$

For $\mathrm{S}_{\max }=350[\mathrm{MPa}], \mathrm{m}=5.3107$, and $\mathrm{C}=2164.7[\mathrm{MPa}]$ (Tab.3), from the formula (6) $\mathrm{N}=1.56 \cdot 10^{4}$ is calculated. 
Tab. 4. Results of the fatigue-life tests under random loading conditions, for the stress value $S_{\max }=350$ [MPa]

\begin{tabular}{|c|c|c|c|c|c|c|c|}
\hline No. of specimen & 1 & 2 & 3 & 4 & 5 & 6 & Mean fatigue life value $\mathrm{N}_{\mathrm{c}}$ \\
\hline Fatigue life $\mathrm{N}_{\mathrm{Ci}}$ & 1.183 & 0.71 & 0.864 & 0.715 & 1.031 & 1.215 & 0.953 \\
\hline
\end{tabular}

As results from the data contained in p. 3 , the spectrum filling factor amounts to $\zeta=0.375$.

On substitution of the above mentioned data to the formula (9) $r=0.36$ is obtained.

The value is contained within the variability limits $r=0.2 \div 0.4$ determined for steel specimens and elements, [10].

\section{Experimental verification of results of fatigue life calculation}

\section{Fatigue life calculations and tests of plain specimens}

Comparison of results of calculations with those of fatigue life tests on the plain specimens made of D16CzATW alloy is mainly aimed at verification of the calculation method assumptions formulated in p. 2 of this work, throughout the whole variability range of the stresses $\mathrm{S}_{\max }$ in the loading spectrum.

The following data were asssumed for the calculations:

- the spectrum filling factor - in accordance with p. 3.2: $\zeta=0.375$

- the power exponent - in accordance with p. $3.5: \mathrm{r}=0.36$

- the Wöhler diagram - in accordance with the data of Tab. 3 - described by the formula:

$$
\log \mathrm{N}=5.3107 \log \frac{2164.7}{\mathrm{~S}_{\max }}
$$

The formula (7) for fatigue life calculation takes the form:

$$
\log \mathrm{N}_{\mathrm{C}}^{\mathrm{obl}}=1.4235 \cdot \log \mathrm{N}
$$

Results of the calculations are presented in Tab. 5, row 4 and 5.

The tests of the plain specimens made of D16CzATW alloy were peformed under the random load conditions described in p. 3.2. The tests were conducted on 30 specimens, for 9 loading levels, namely: 450, 440, 400, 360, 350, 320, 300, 280 and $250[\mathrm{MPa}]$.

Results of the tests together with the Gassner diagram based on them are presented in Fig. 8.

The diagram is described by the formula:

$$
\log \mathrm{N}_{\mathrm{C}}^{\mathrm{ex}}=7.4184 \log \frac{2248}{\mathrm{~S}_{\max }}
$$

Results of the calculations of $\mathrm{N}_{\mathrm{C}}{ }^{\text {ex }}$ values from the formula (10) for selected levels of $\mathrm{S}_{\max }$, are presented in Tab. 5, row 6 and 7.

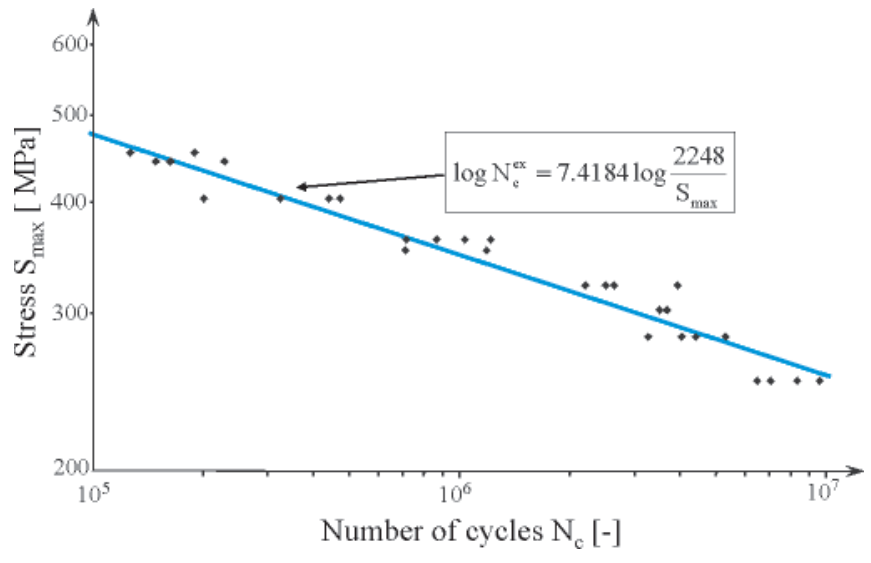

Fig. 8. Gassner fatigue life diagram (a) for plain specimens made of D16CzATW aluminium alloy

Comparison of the Gassner diagrams determined on the basis of the calculations and tests is shown in Fig. 9.

From the diagrams of Fig. 9 result only slight differences between the calculated fatigue life and the experimentally determined. The relative deviation calculated from the formula (11) amounts - in extreme cases - to: $\delta_{\mathrm{N}}=5.4 \%$ for $\mathrm{S}_{\max }=450$ $[\mathrm{MPa}], \delta_{\mathrm{N}}=10 \%$ for $\mathrm{S}_{\max }=150 \mathrm{MPa}$.

$$
\delta_{\mathrm{N}}=\frac{\mathrm{N}_{\mathrm{C}}^{\mathrm{ex}}-\mathrm{N}_{\mathrm{C}}^{\mathrm{obl}}}{\mathrm{N}_{\mathrm{C}}^{\mathrm{ex}}} \cdot 100 \%
$$

The $\delta_{\mathrm{N}}$ values which do not exceed $10 \%$ in relation to the results of the fatigue life calculations, should be considered very small. The very high calculation accuracy results mainly from the way of determining the power exponent $r$ in the formula (8) on the basis of the experiment for the mean values of $\mathrm{S}_{\max }$. However this analysis is aimed at showing that in the whole $\mathrm{S}_{\max }$ variability range from 150 to $450[\mathrm{MPa}]$ the assumptions for the calculation method are correct.

\section{Fatigue life calculations and tests of the notched specimens (acc. Fig. 6b)}

The analysis described in this point is mainly aimed at demonstrating that the data concerning the exponent $r$ determined from standard plain specimens can be used as the basis for the calculations in the case of notched specimens and complex structural elements.

The testing and calculating methods are the same as in p. 3.6a, it means that Wöhler fatigue diagram, loading spectrum

Tab. 5. Results of the fatigue life calculations and tests of the plain specimens made of D16CzATW alloy

\begin{tabular}{|c|c|c|c|c|c|c|}
\hline 1. & $\mathrm{~S}_{\max }$ & 150 & 200 & 250.4 & 300 & 350 \\
\hline 2. & $\log \mathrm{N}$ & 6.1443 & 5.4823 & 4.9687 & 4.5490 & 4.1944 \\
\hline 3. & $\mathrm{~N}$ & $1.4 \cdot 10^{6}$ & $3.036 \cdot 10^{5}$ & $9.3 \cdot 10^{4}$ & $3.54 \cdot 10^{4}$ & $1.56 \cdot 10^{4}$ \\
\hline 4. & $\log \mathrm{N}_{\mathrm{C}}{ }^{\text {obl }}$ & 8.7427 & 7.8041 & 7.0729 & 6.4755 & 5.9707 \\
\hline 5. & $\mathrm{~N}_{\mathrm{C}}^{\text {obl }}$ & $5.53 \cdot 10^{8}$ & $6.37 \cdot 10^{7}$ & $1.18 \cdot 10^{7}$ & $2.99 \cdot 10^{6}$ & $9.35 \cdot 10^{5}$ \\
\hline 6. & $\log \mathrm{N}_{\mathrm{C}}^{\text {ex }}$ & 8.7001 & 7.7759 & 7.0588 & 6.4728 & 5.9777 \\
\hline 7. & $\mathrm{~N}_{\mathrm{C}}{ }^{\mathrm{ex}}$ & $5.014 \cdot 10^{8}$ & $5.97 \cdot 10^{7}$ & $1.1 \cdot 10^{7}$ & $2.87 \cdot 10^{6}$ & $9.5 \cdot 10^{5}$ \\
\hline
\end{tabular}


Plain specimen, material: D16CzATW aluminium alloy

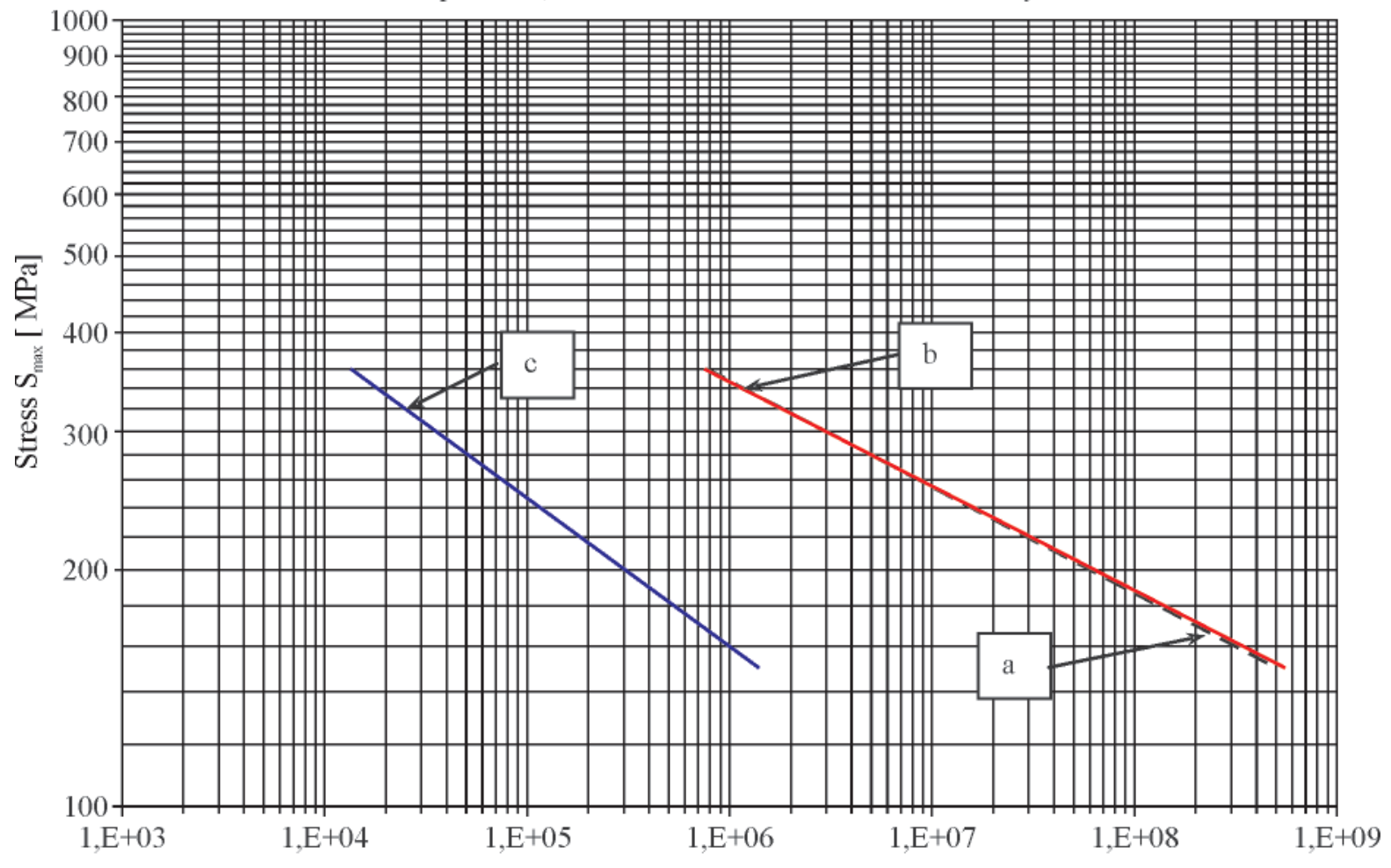

Number of cycles $\mathrm{N}$

Fig. 9. Fatigue life diagrams for plain specimens made of D16CzATW aluminium alloy: a) experimentally determined under random loading conditions, b) based on calculations acc. formula (4a), shown against the Wöhler diagram (c)

parameters as well as values of the power exponent $r$ constitute the basis for the calculations. The experimental tests of the elements were conducted under the random loading conditions described in p. 3.2.

The Wöhler fatigue diagram for the plate with rivet holes, made of D16CzATW aluminum alloy, is shown in Fig. 10.

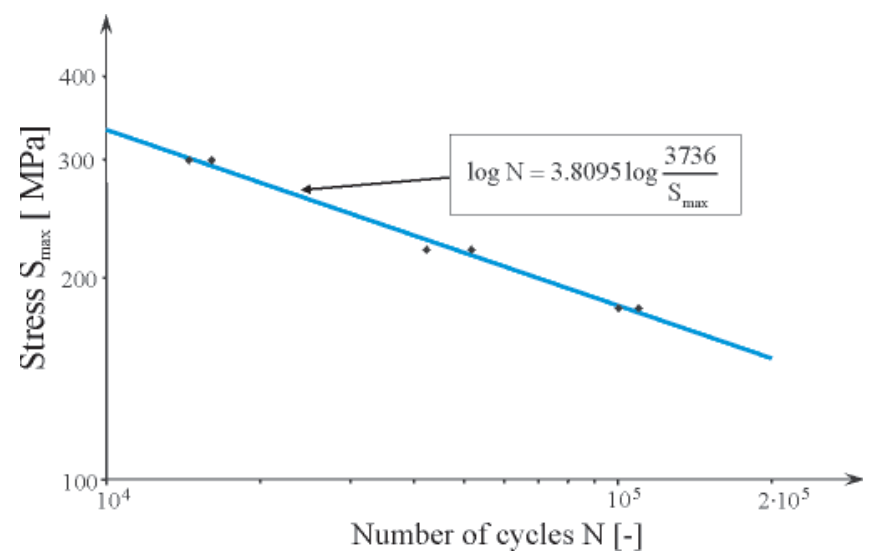

Fig. 10. The Wöhler fatigue diagram for the plate with rivet holes (acc. Fig.6b), made of D16CzATW aluminum alloy
The diagram is described by the formula:

$$
\log \mathrm{N}=3.8095 \cdot \log \frac{3736}{\mathrm{~S}_{\max }}
$$

Results of the fatigue life tests under operational loading are shown in the Gassner diagram form in Fig. 11, and the formula (13) provides its description.

Fig. 11. The Gassner fatigue diagram for the plate with rivet holes (acc. Fig.6b), made of D16CzATW aluminum alloy

$$
\log \mathrm{N}_{\mathrm{C}}^{\mathrm{ex}}=4.052 \log \frac{9080}{\mathrm{~S}_{\max }}
$$

The results of the calculations and tests are collected in Tab. 6, like in the case of the plain specimens. The data given in the row 4 and 5, Tab. 6, were calculated on the basis of the formula (4a).

The results of the calculations and tests given in Tab. 6 are graphically presented in the diagrams of Fig. 12.

The maximum relative differences between the calculation and test results, determined from the formula (11) amount to: $\delta_{\mathrm{N}}=-124 \%$ for $\mathrm{S}_{\max }=150[\mathrm{MPa}]$, and $\delta_{\mathrm{N}}=42 \%$ for $\mathrm{S}_{\max }=400[\mathrm{MPa}]$.

Tab. 6. Results of the fatigue life calculations and tests of the plates with rivet holes (acc. Fig.6b), made of D16CzATW alloy

\begin{tabular}{|c|c|c|c|c|c|c|}
\hline 1. & $\mathrm{~S}_{\max }$ & 150 & 200 & 250 & 300 & 350 \\
\hline 2. & $\log \mathrm{N}$ & 5.3193 & 4.8433 & 4.4741 & 4.1725 & 3.9174 \\
\hline 3. & $\mathrm{~N}$ & $2.9 \cdot 10^{5}$ & $6.97 \cdot 10^{4}$ & $2.98 \cdot 10^{4}$ & $1.49 \cdot 10^{4}$ & $8.27 \cdot 10^{3}$ \\
\hline 4. & $\log \mathrm{N}_{\mathrm{C}}{ }^{\text {obl }}$ & 7.5720 & 6.8944 & 6.3689 & 5.9396 & 5.5764 \\
\hline 5. & $\mathrm{~N}_{\mathrm{C}}^{\text {obl }}$ & $3.73 \cdot 10^{7}$ & $7.84 \cdot 10^{6}$ & $2.34 \cdot 10^{6}$ & $8.7 \cdot 10^{5}$ & $3.77 \cdot 10^{5}$ \\
\hline 6. & $\log \mathrm{N}_{\mathrm{C}}^{\text {ex }}$ & 7.2206 & 6.7144 & 6.3217 & 6.0008 & 5.7296 \\
\hline 7. & $\mathrm{~N}_{\mathrm{C}}{ }^{\text {x }}$ & $1.66 \cdot 10^{7}$ & $5.18 \cdot 10^{6}$ & $2.1 \cdot 10^{6}$ & $1.0 \cdot 10^{6}$ & $5.36 \cdot 10^{5}$ \\
\hline
\end{tabular}




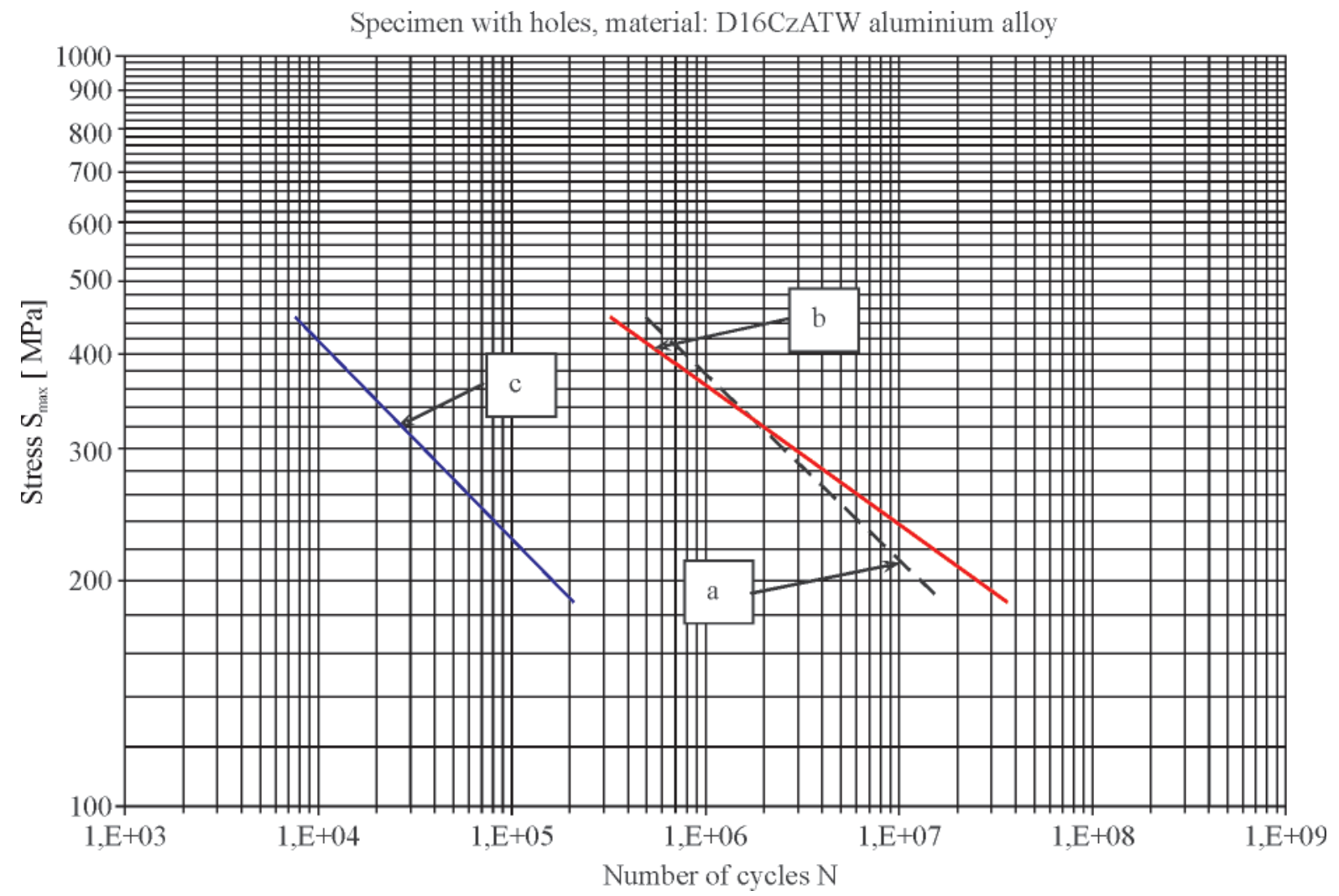

Fig. 12. Results of the fatigue life calculations and tests of the plates with rivet holes (acc. Fig. 6b), made of D16CzATW aluminum alloy: a) experimentally determined under random load conditions, b) based on the calculations, shown against the Wöhler diagram (c)

The above presented differences in the results of fatigue life analysis are relatively small as compared with the results available by means of other methods.

\section{Fatigue life calculations and tests of the riveted elements (acc. Fig. 6c)}

As the run of calculations and tests of the plates with rivet holes and the riveted elements is identical, in this point only the relevant formulae, diagrams and table are included.

In Fig. 13 the Wöhler diagram for the riveted element acc. Fig. $6 \mathrm{c}$ is presented, and in Fig. 14 - the results of the tests under operational loading conditions.

The diagrams of Fig. 13 and 14 are respectively described as follows:

- the Wöhler diagram

$$
\log \mathrm{N}=5.048 \log \frac{2154.8}{\mathrm{~S}_{\max }}
$$

- the Gassner diagram

$$
\log \mathrm{N}_{\mathrm{C}}^{\mathrm{ex}}=4.529 \log \frac{6912}{\mathrm{~S}_{\max }}
$$

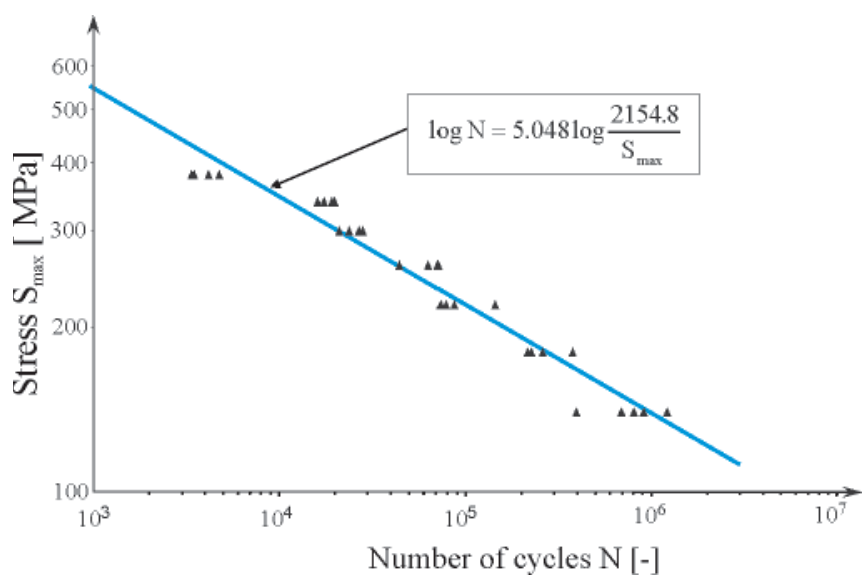

Fig. 13. The Wöhler diagram for the riveted element (acc. Fig. 6c) made of D16CzATW aluminum alloy

The fatigue life according to the proposed method was calculated by using the formula (4a).

In the diagrams of Fig. 15 the results of the calculations and tests given in Tab. 7 are graphically compared with the Wöhler diagram.

Tab. 7. Results of the fatigue life calculations and tests of the riveted elements (acc. Fig.6c), made of D16CzATW alloy

\begin{tabular}{|c|c|c|c|c|c|c|}
\hline 1. & $\mathrm{~S}_{\max }$ & 150 & 200 & 250 & 300 & 350 \\
\hline 2. & $\log \mathrm{N}$ & 5.8421 & 5.2114 & 4.7222 & 4.3225 & 3.9846 \\
\hline 3. & $\mathrm{~N}$ & $6.9 \cdot 10^{5}$ & $1.6 \cdot 10^{5}$ & $5.3 \cdot 10^{4}$ & $2.1 \cdot 10^{4}$ & $9.65 \cdot 10^{3}$ \\
\hline 4. & $\log \mathrm{N}_{\mathrm{C}}^{\text {obl }}$ & 8.3162 & 7.4184 & 6.7220 & 6.1530 & 5.6721 \\
\hline 5. & $\mathrm{~N}_{\mathrm{C}}{ }^{\text {bl }}$ & $2.07 \cdot 10^{8}$ & $2.6 \cdot 10^{7}$ & $5.27 \cdot 10^{6}$ & $1.4 \cdot 10^{6}$ & $4.6 \cdot 10^{5}$ \\
\hline 6. & $\log \mathrm{N}_{\mathrm{C}}{ }^{\mathrm{ex}}$ & 7.5340 & 6.9682 & 6.5293 & 6.1584 & 5.8675 \\
\hline 7. & $\mathrm{~N}_{\mathrm{C}}{ }^{\mathrm{ex}}$ & $3.4 \cdot 10^{7}$ & $9.3 \cdot 10^{6}$ & $3.4 \cdot 10^{6}$ & $1.4 \cdot 10^{6}$ & $7.37 \cdot 10^{5}$ \\
\hline
\end{tabular}




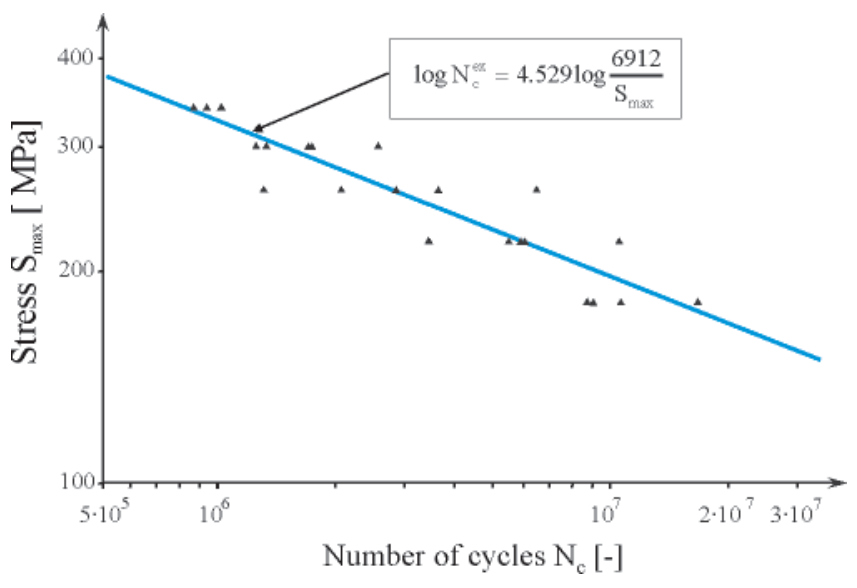

Fig. 14. The Gassner fatigue life diagram for the riveted element (acc. Fig. 6c) made of D16CzATW aluminum alloy

As results from the comparison, the greatest differences between the experimentally determined fatigue life and that calculated appear at the ends of the stress range used for the analysis in question. The relative values of the differences calculated according to the formula (11) amount to: $\delta_{\mathrm{N}}=0.37$ for $\mathrm{S}_{\max }=250[\mathrm{MPa}]$, and $\delta_{\mathrm{N}}=-5.08$ for $\mathrm{S}_{\max }=150[\mathrm{MPa}]$.

The calculated differences for the riveted element are greater than those for the plate with rivet holes. The fact results from the greater spread of results of fatigue life tests of the riveted element which is deemed incommensurably more complex from the point of view of run of fatigue process depending on various factors.

If the spread band of the test results is taken into account on the confidence level of 0.95 then the fatigue life calculation results are contained within the band.

\section{SUMMARY}

- The discussed calculation method for fatigue life of structural elements, based on statistical relations between the fatigue diagrams determined under constant - amplitude loading conditions (Wöhler diagrams) and those determined under random loading conditions characteristic for operational conditions of structural elements (Gassner diagrams), constitutes an essential contribution to the calculation methods based on phenomenological hypotheses of fatigue damage summation.

Formulation of the assumptions for the proposed method is described in the publications [2] and [17] which also contain the experimental verification of the method, based on the comparison between the calculation results and those obtained from the tests on steel elements, performed in the loading conditions characterized by different values of the spectrum filling factor $\zeta(0.34 ; 0.56 ; 0.77)$. The crucial conclusion resulting from the analysis is that the analyzed calculation method may be effectively applied to load spectra irrespective of values of their factor $\zeta$.

- In this work the applicability analysis of the specimens and structural elements made of the D16CzATW aluminum alloy used in aircraft industry, has been performed. And, its original element, as compared with earlier publications, is the proof that the parameters which appear in the formula for calculating the fatigue life determined from standard specimens, are also applicable to calculations of complex structural elements; the statement mainly concerns value of the power exponent $r$ appearing in the formulae (5) and (7).

- The comparative analysis of the calculation and experimental test results showed a satisfactory conformity and possible practical application of the proposed method to structural

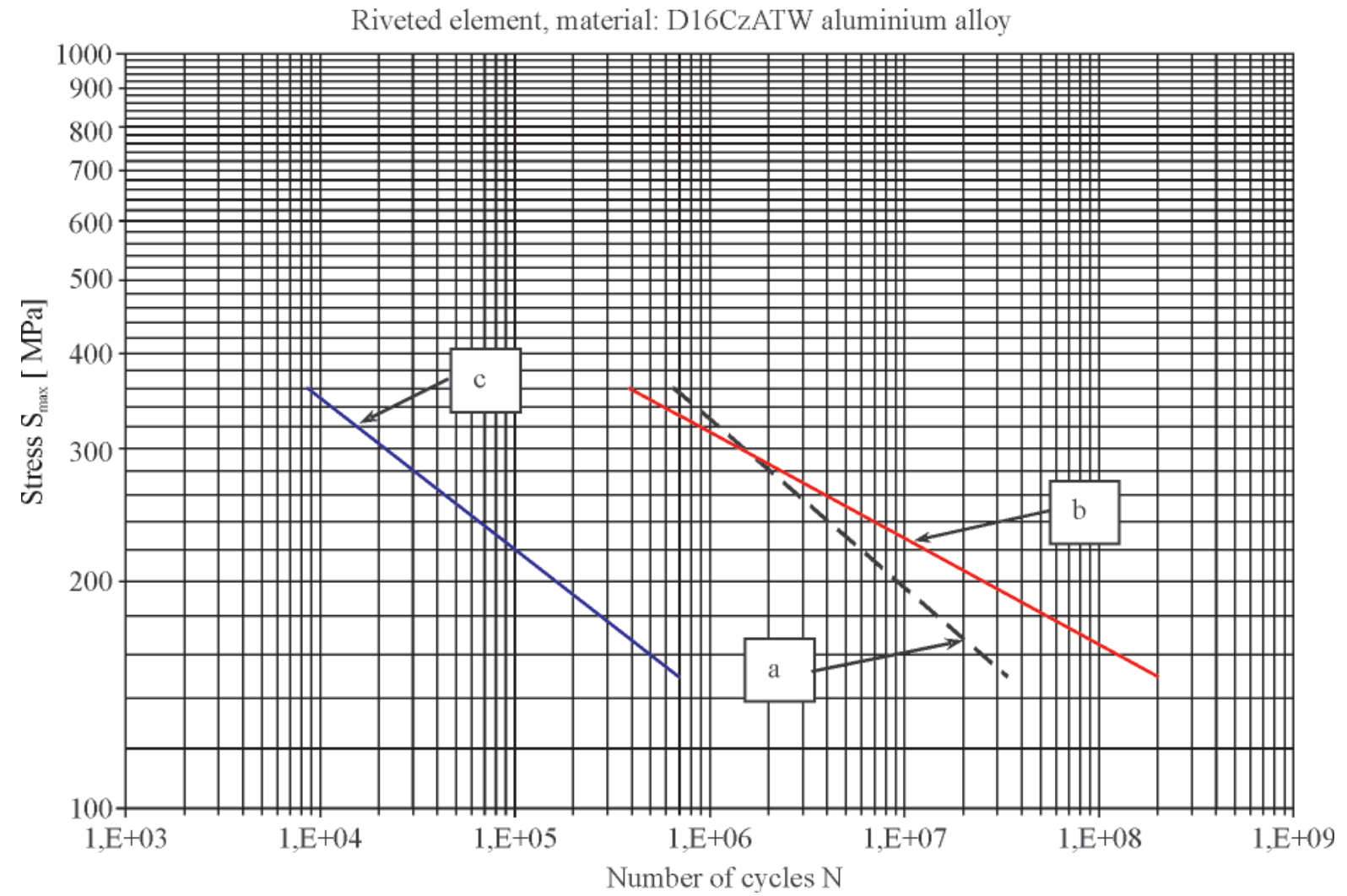

Fig. 15. Graphical comparison of the results of the calculations and tests presented in Tab.7: a) experimentally determined under random load conditions; b) based on the calculations; shown against the Wöhler diagram (c) 
design process when, as real material objects are lacking, only scarce data on operational conditions (data on measured loads) and on design features of such objects (being in statu nascendi), are at one's disposal.

This work has been elaborated in the frame of the research project No. 7 T07B 01018 financially supported by the Ministry of Science and Higher Education.

\section{NOMENCLATURE}

\begin{tabular}{|c|c|}
\hline & - spectrum filling factor \\
\hline & - stress (general notation), $[\mathrm{MPa}]$ \\
\hline $\mathrm{S}_{\max }$ & $\begin{array}{l}\text { maximum stress: in a sinusoidal cycle, an } \\
\text { analyzed section of random stresses (e.g. } \\
\text { a measuring section of operational loading), } \\
\text { loading spectrum, or loading programme, } \\
\text { [MPa] }\end{array}$ \\
\hline $\mathrm{S}_{\min }$ & $\begin{array}{l}\text { minimum stress: in a sinusoidal cycle, an } \\
\text { analyzed section of random stresses (e.g. } \\
\text { a measuring section of operational loading), } \\
\text { loading spectrum, or loading programme, } \\
\text { [MPa] }\end{array}$ \\
\hline $\mathrm{S}_{\mathrm{m}}$ & $\begin{array}{l}\text { mean stress value: in a sinusoidal cycle, an } \\
\text { analyzed section of random stresses (e.g. } \\
\text { a measuring section of operational loading), } \\
\text { loading spectrum, or loading programme, } \\
\text { [MPa] }\end{array}$ \\
\hline $\mathrm{S}_{\mathrm{a}}$ & - stress amplitude in a sinusoidal cycle \\
\hline $\mathrm{S}_{\mathrm{ai}}^{\mathrm{a}}$ & $\begin{array}{l}\text { - stress amplitude in loading cycles: sinusoidal } \\
\text { of i-th step, a loading spectrum or loading } \\
\text { programme }\end{array}$ \\
\hline $\mathrm{i}$ & - number of a step in a loading spectrum or \\
\hline$=\frac{n_{i}}{n}-\frac{n_{\lambda i}}{2}$ & loading programme \\
\hline $\mathrm{t}_{\mathrm{i}}=\frac{1}{\mathrm{n}_{\mathrm{c}}}=\frac{\mathrm{Ml}_{1}}{\mathrm{n}_{\lambda \mathrm{c}}}$ & $\begin{array}{l}\text { - fraction of number of } \mathrm{S}_{\mathrm{ai}}-\text { amplitude cycles in } \\
\text { total number of cycles appearing in a loading } \\
\text { spectrum or programme }\end{array}$ \\
\hline$n_{i}$ & $\begin{array}{l}\text { - number of } \mathrm{S}_{\mathrm{a}} \text { - amplitude cycles appearing in } \\
\text { a loading spectrum }\end{array}$ \\
\hline $\mathrm{n}_{\mathrm{c}}$ & $\begin{array}{l}\text { - total number of cycles within a loading } \\
\text { spectrum }\end{array}$ \\
\hline $\mathrm{n}_{\lambda \mathrm{i}}$ & $\begin{array}{l}\text { - number of } \mathrm{S}_{\mathrm{ai}} \text { - amplitude cycles within } \\
\text { a loading programme period }\end{array}$ \\
\hline $\mathrm{n}_{\lambda c}$ & $\begin{array}{l}\text { - total number of cycles within a loading } \\
\text { programme }\end{array}$ \\
\hline$\lambda$ & $\begin{array}{l}\text { - number of repetitions of a loading programme } \\
\text { period up to fatigue fracture }\end{array}$ \\
\hline $\mathrm{N}$ & - number of cycles (general notation) \\
\hline $\mathrm{N}_{\mathrm{i}}$ & $\begin{array}{l}\text { - number of cycles to fatigue fracture in } \\
\text { sinusoidal } \mathrm{S}_{\mathrm{ai}}-\text { amplitude loading conditions }\end{array}$ \\
\hline & - fatigue life $^{\text {al }}$ \\
\hline $\mathrm{F}(\mathrm{S})$ & - distribution of values of sinusoidal cycles \\
\hline $\mathrm{m}_{\mathrm{o}}$ & $\begin{array}{l}\text { - parameter in the formulae which describe } \\
\text { Wöhler diagram }\end{array}$ \\
\hline Cim & $\begin{array}{l}\text { - parameters in the formulae which describe } \\
\text { Gassner fatigue life diagram, Eq. (3) }\end{array}$ \\
\hline $\mathrm{C}_{\mathrm{o}}$ & $\begin{array}{l}\text { - constant value in the formula which describe } \\
\text { Wöhler diagram of exponential form }\end{array}$ \\
\hline $\mathrm{S}_{\mathrm{f}(0)}$ & $\begin{array}{l}\text { - fatigue limit at the stress ratio } \mathrm{R}=0 \text { (pulsating } \\
\text { load) }\end{array}$ \\
\hline$\delta_{\mathrm{w}}$ & $\begin{array}{l}\text { - relative difference between fatigue life test and } \\
\text { calculation results (see Eq. (11)). }\end{array}$ \\
\hline
\end{tabular}

Indices

ex $\quad-$ stands for operational results or values

obl $\quad-$ stands for calculation results or values.

\section{BIBLIOGRAPHY}

1. Manson S.S.,Halford G.R.: Re-Examination of Cumulative Fatigue Damage Analysis - an Engineering Perspective. Engineering Fracture Mechanics, Vol.25, No. 5/6, 1986

2. Szala J., Boroński D.: Material fatigue state assessment in diagnostics of machines and devices (in Polish). Wydawnictwo ITE-PIB (Publishing House of Institute of the Technology of the Exploitation - State Research Institute), Bydgoszcz, 2008

3. Sevensson T., Johannesson P., de Mare J.: Fatigue life prediction based on variable amplitude tests-specific applications. International Journal of Fatigue, 27, 2005

4. Liu Y., Mahadevans S.: Stochastic fatigue damage modeling under variable amplitude loading. International Journal of Fatigue, 29, 2007

5. Buch A.: Prediction of the comparative fatigue performance for realistic loading distributions. Prog. Aerospace Sci. Vol. 33, 1997

6. Sonsino C.M.: Fatigue testing under variable amplitude loading. International Journal Fatigue, 29, 2007

7. Kocańda S., Szala J.: Essentials of fatigue calculations (in Polish). PWN (State Scientific Publishing House), Warsaw, 1997

8. Soprotivlenie ustalosti metalom i splavov. Kiev Naukowe Dumka, 1987

9. Boyer H. E.: Atlas of Fatigue Curves. American Society for Metals (ASM), Ohio, 2003

10.Szala J.: Fatigue life assessment of machines under random and programmed loading conditions (in Polish). Monograph, Mechanika 22, Wydawnictwo ATR (Publishing House of Technical Agricultural Academy), Bydgoszcz, 1980

11.Lehman R.: Über die Gültigkeit der Hypothese der Linearen Schadens-akumulation. Maschinenbautechnik 5, 1970

12.Haibach E.: Probleme der Betriebsfestigkeit von metalischen Konstruktionsteilen. VDI- Z133, 1971, Nr 5, 1.297/403

13.Osterman H.: Die Lebensdauerabschätzung bei Sonderkollektiven. LBF-Bericht Nr TB-80, 1968

14.Haibach E.: Betriebs-Festigkeit. VDI Verlag GmbH, Düsseldorf, 1989

15.Fricke W., Petershagen, Paetzold H.: Fatigue Strength of Ship Structures, Part I: Basic Principles. GL-Technology, Information from Germanischer Lloyd Group, $\mathrm{Nr}$ 1/97, Hamburg, 1997

16.Fricke W., Petershagen, Paetzold H.: Fatigue Strength of Ship Structures, Part II: Examples. GL-Technology, Information from Germanischer Lloyd Group, Nr 1/98, Hamburg, 1998

17.Szala J.: On a fatigue calculation method for structural elements under stochastic loading conditions (in Polish). Archiwum Budowy Maszyn (Archive of Machinery Engineering), Vol. XXIX, No. $3 \div 4,1982$

18.Szala J.: Selected fatigue-life problems of elements of ship machines and devices (in Polish). Proc. the Jubilee Scientific Conference: Research \& Development - a chance for Polish shipbuilding industry, Ship Design and Research Centre, Gdańsk, 2001.

\section{CONTACT WITH THE AUTHORS}

Józef Szala, Prof., Grzegorz Szala, Ph. D.

Faculty of Mechanical Engineerig, University of Technology and Life Science, Prof. S. Kaliskiego 7 85-763 Bydgoszcz, POLAND e-mail: jszpkm@utp.edu.pl 